\title{
Relation of atrial natriuretic peptides to left ventricular systolic and diastolic function in heart failure
}

\author{
Anke A.M. Wijbenga a,*, Aggie H.M.M. Balk ${ }^{a}$, Fokke A.M. Jonkman ${ }^{a}$, \\ Frans Boomsma ${ }^{b}$, Maarten L. Simoons ${ }^{\mathrm{a}}$, Arie J. Man in 't Veld ${ }^{\mathrm{b}}$ \\ ${ }^{a}$ Heart Center Bd 381, University Hospital Rotterdam, Dr Molewaterplein 40, 3015 GD Rotterdam, The Netherlands \\ ${ }^{\mathrm{b}}$ Department of Internal Medicine I, University Hospital Rotterdam, Rotterdam, The Netherlands
}

\begin{abstract}
Background: Plasma concentrations of atrial natriuretic peptides are correlated with atrial pressures, as are left ventricular ejection fraction and left ventricular filling abnormalities. Aims: This study investigated the relation of atrial natriuretic peptides to both left ventricular systolic and diastolic function in heart failure. Methods: Plasma concentrations of atrial natriuretic peptide and N-terminal pro-atrial natriuretic peptide were measured in 63 patients with chronic heart failure and left ventricular systolic dysfunction. According to Doppler transmitral flow measurements, 19 patients had a restrictive and 44 patients had a non-restrictive left ventricular filling pattern. Results: Plasma concentrations of atrial natriuretic peptide and $\mathrm{N}$-terminal pro-atrial natriuretic peptide were higher in patients with a restrictive filling pattern than in patients with a non-restrictive filling pattern ( $197 \mathrm{vs.} 75 \mathrm{pmol} / 1, P<0.0001$ and $1.14 \mathrm{vs.} 0.45 \mathrm{nmol} / 1, P<0.0001)$. In univariate analysis, atrial natriuretic peptide and $\mathrm{N}$-terminal pro-atrial natriuretic peptide correlated with deceleration time, E/A ratio and left ventricular ejection fraction. In multivariate analysis, both peptides appeared independently related to left ventricular ejection fraction and left ventricular filling pattern. Conclusion: In patients with chronic heart failure, atrial natriuretic peptides provide information on left ventricular systolic as well as diastolic function. (c) 1999 European Society of Cardiology. All rights reserved.
\end{abstract}

Keywords: Heart failure; Atrial natriuretic peptide; N-terminal pro-atrial natriuretic peptide; Left ventricular ejection fraction; Left ventricular filling pattern

\section{Introduction}

Atrial natriuretic peptide (ANP) and the N-terminal fragment of its prohormone (N-terminal proANP) are known to be released in response to atrial stretch and to be closely correlated with atrial pressures in patients with heart failure [1,2]. Moreover, plasma atrial natriuretic peptide concentrations have been shown to be increased in patients with left ventricular systolic dysfunction and to be related to severity of heart failure [3-5].

\footnotetext{
${ }^{*}$ Corresponding author. Tel.: +3110 4633949; fax: +3110 40849484; e-mail: wybenga@card.azr.nl
}

In addition to left ventricular systolic dysfunction, abnormalities of diastolic function are common in patients with heart failure. Impaired relaxation in the presence of normal filling pressures results in reduced early diastolic filling. A restrictive filling pattern, on the other hand, is characterized by a fast, but abruptly ending increase in early filling reflecting diminished ventricular compliance and is associated with increased filling pressures, more severe disease and a poor prognosis [6-9].

In patients with left ventricular systolic dysfunction, a relationship between restrictive left ventricular filling patterns and elevated natriuretic peptide concentrations has been described [10]. However, whether this association resulted from the evident differences 
in left ventricular ejection fraction remained undefined. A clear understanding of the determinants of atrial natriuretic peptide concentrations in patients with heart failure is important for a correct interpretation of these markers of severity of the disease. For that reason, we studied the direct relationship between plasma atrial natriuretic peptide concentrations and left ventricular systolic as well as diastolic function in patients with heart failure.

\section{Methods}

\subsection{Study population}

Within the framework of a comprehensive out-patient heart failure study protocol, 69 consecutive patients with chronic heart failure and left ventricular systolic dysfunction due to coronary artery disease or dilated cardiomyopathy underwent several non-invasive cardiovascular tests, among which echocardiography and blood sampling for measurement of plasma atrial natriuretic peptide concentrations. For the present study, only patients who were in sinus rhythm were eligible. The study population consisted of 63 patients, 54 men and nine women, aged $61 \pm 9$ years. Clinical characteristics are presented in Table 1. Echocardiography and blood sampling were performed on the same day in the late morning, 2-3 $h$ after administration of heart failure medication, in

Table 1

Clinical characteristics for all patients and for patients with restrictive and non-restrictive left ventricular filling patterns

\begin{tabular}{lcll}
\hline & All patients & $\begin{array}{l}\text { Non-restrictive } \\
\text { pattern }\end{array}$ & $\begin{array}{l}\text { Restrictive } \\
\text { pattern }\end{array}$ \\
\hline$n$ & 63 & 44 & 19 \\
Age (years) & $61 \pm 10$ & $62 \pm 8$ & $58 \pm 13$ \\
Gender (male) & $54(86 \%)$ & $38(86 \%)$ & $16(84 \%)$ \\
Aetiology (CAD) & $40(63 \%)$ & $27(61 \%)$ & $13(68 \%)$ \\
MR ( $\geq$ grade 2) & $5(8 \%)$ & $3(7 \%)$ & $2(10 \%)$ \\
Heart rate (b.p.m.) & $72 \pm 11$ & $71 \pm 10$ & $75 \pm 14$ \\
LVEF (\%) & $32 \pm 7$ & $33 \pm 6$ & $30 \pm 7$ \\
NYHA classification & $1.9 \pm 0.6$ & $1.8 \pm 0.6$ & $2.3 \pm 0.6 *$ \\
Medication & & & \\
$\quad$ ACE inhibitors & $57(91 \%)$ & $40(91 \%)$ & $17(90 \%)$ \\
Diuretics & $47(75 \%)$ & $29(66 \%)$ & $18(95 \%)^{* *}$ \\
Digoxin & $31(49 \%)$ & $20(46 \%)$ & $11(58 \%)$ \\
Nitrates & $20(32 \%)$ & $15(34 \%)$ & $5(26 \%)$ \\
\hline
\end{tabular}

Notes. Data are expressed as mean \pm S.D. or number (\%). ${ }^{*} P=$ 0.003 ; ${ }^{* *} P=0.02$, patients with non-restrictive vs. restrictive left ventricular filling patterns. CAD, coronary artery disease; $M R$, mitral regurgitation; LVEF, left ventricular ejection fraction; NYHA, New York Heart Association; ACE, angiotensin converting enzyme. order to standardize for diurnal variations of measurement parameters. The investigation conforms with the principles outlined in the Declaration of Helsinki.

\subsection{Echocardiography}

Left ventricular ejection fraction was calculated from the apical four-chamber and long-axis views using a biplane disk-method [11]. Mean values were obtained by averaging three consecutive beats. Mitral regurgitation was identified using continuous wave Doppler echocardiography and graded on a scale of one to four [12]. Left ventricular inflow velocities were recorded from the apical four-chamber view using pulsed Doppler echocardiography with the sample volume placed between the tips of the mitral leaflets. Doppler measurements were made by manual tracing of the outermost portion of the velocity contour using an off-line computer, a digitizing tablet and a dedicated software program [13]. Parameters of left ventricular filling included peak early $(E)$ and peak atrial (A) filling velocities, the E/A ratio and deceleration time of peak early filling to baseline. Mean values were obtained by averaging 10 consecutive beats. Heart rate was averaged from the same beats. Patients were classified as having a restrictive or a non-restrictive left ventricular filling pattern based on $\mathrm{E} / \mathrm{A}$ ratio and deceleration time: an $\mathrm{E} / \mathrm{A}$ ratio $\geq 2$ was considered to be restrictive, whereas an $\mathrm{E} / \mathrm{A}$ ratio $\leq 1$ was considered to be non-restrictive. In case the $\mathrm{E} / \mathrm{A}$ ratio was between 1 and 2, a deceleration time of $\leq 150 \mathrm{~ms}$ was considered to be restrictive and a deceleration time $>150 \mathrm{~ms}$ was considered to be non-restrictive $[14,15]$.

\subsection{Atrial natriuretic peptides}

Venous blood samples were drawn after $30 \mathrm{~min}$ of supine rest and collected in pre-chilled polystyrene tubes containing EDTA and aprotinine. The tubes were placed on ice and centrifuged within $30 \mathrm{~min}$ from sampling in a refrigerated centrifuge for $10 \mathrm{~min}$ at $3000 \times \mathrm{g}$. Plasma was stored in polyethylene tubes at $-70^{\circ} \mathrm{C}$ until analysed. All analyses took place in the Cardiovascular Research Laboratory, University Hospital Rotterdam, The Netherlands. Plasma concentrations of ANP were determined with a commercially available radioimmunoassay kit (Nichols Institute, Wijchen, The Netherlands) after extraction from plasma. $\mathrm{N}$-terminal proANP concentrations were measured directly in plasma using a commercially available radioimmunoassay kit from Biotop, Oulu, Finland [16].

\subsection{Statistical analysis}

Comparisons between patients with restrictive and 
non-restrictive left ventricular filling patterns were made by unpaired $t$-tests for continuous data and $\chi^{2}$ tests for categorical data. Univariate linear regression analysis was used to test the relation between atrial natriuretic peptide concentrations and deceleration time, E/A ratio and left ventricular ejection fraction. Multivariate linear regression analysis was used to evaluate the relation of plasma ANP and $\mathrm{N}$-terminal proANP concentrations to left ventricular filling pattern, left ventricular ejection fraction, New York Heart Association functional class, diuretic therapy, heart rate, age and an interaction term between left ventricular filling pattern and age. Because of their skewed distribution, the natural logarithmic transformed values of ANP and N-terminal proANP were used in the analyses. Data are described as mean \pm S.D. unless otherwise specified. All analyses were performed with SPSS for Windows (release 6.1). Statistical significance was defined as $P<0.05$.

\section{Results}

\subsection{Group characteristics}

According to transmitral flow parameters, 19 patients had a restrictive left ventricular filling pattern, whereas 44 patients had a non-restrictive left ventricular filling pattern. Both groups were comparable as regards age, gender, aetiology of heart failure, heart rate, left ventricular ejection fraction, presence of more than mild mitral regurgitation ( $\geq$ grade 2 ) on echocardiography and use of angiotensin converting enzyme inhibitors, digoxin and nitrates. However, patients with a restrictive left ventricular filling pattern were more symptomatic and were using diuretics more frequently than patients with a non-restrictive pattern (Table 1).

\subsection{Univariate analysis}

Plasma concentrations of ANP and N-terminal proANP were higher in patients with a restrictive filling pattern compared to patients with a non-restrictive filling pattern (Fig. 1). Median (and range) for ANP (pmol/l) in patients with a restrictive vs. patients with a non-restrictive pattern were 197 $(83-358)$ vs. $75(16-197)(P<0.0001)$ and for $\mathrm{N}$ terminal proANP (nmol/1) $1.14(0.52-2.42)$ vs. 0.45 $(0.10-1.26)(P<0.0001)$. For the whole group, ANP correlated well with $\mathrm{N}$-terminal proANP $(r=0.89$, $P<0.0001$ ). In univariate linear regression analysis, ANP correlated with deceleration time $(r=-0.52$, $P<0.0001)$ (Fig. 2A), E/A ratio $(r=0.50, P<0.0001)$ (Fig. 3A) and left ventricular ejection fraction $(r=$ $-0.37, P=0.003$ ). Similarly, N-terminal proANP was related to deceleration time $(r=-0.48, P=0.0001)$
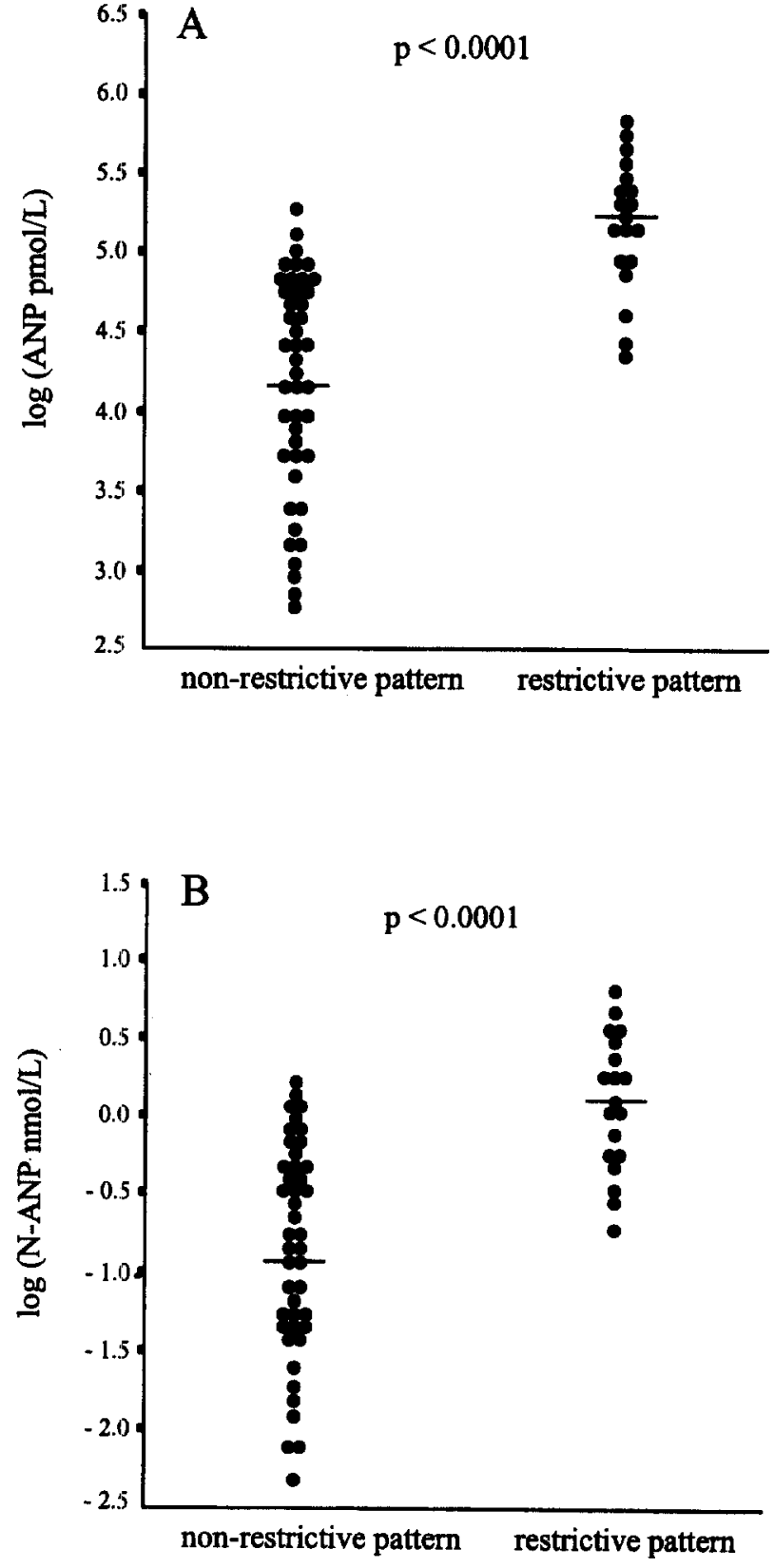

Fig. 1. Plasma concentrations of (A) atrial natriuretic peptide (ANP) and (B) N-terminal proANP according to left ventricular filling pattern.

(Fig. 2Bi), E/A ratio $(r=0.48, P=0.0001)$ (Fig. 3B) and left ventricular ejection fraction $(r=-0.38, P=$ 0.002 ).

\subsection{Multivariate analysis}

In order to evaluate the relationship between atrial natriuretic peptide concentrations, left ventricular filling pattern and left ventricular systolic function, separate multivariate linear regression analyses were performed for each peptide. Since age influences atrial natriuretic peptide concentrations [17] as well left 

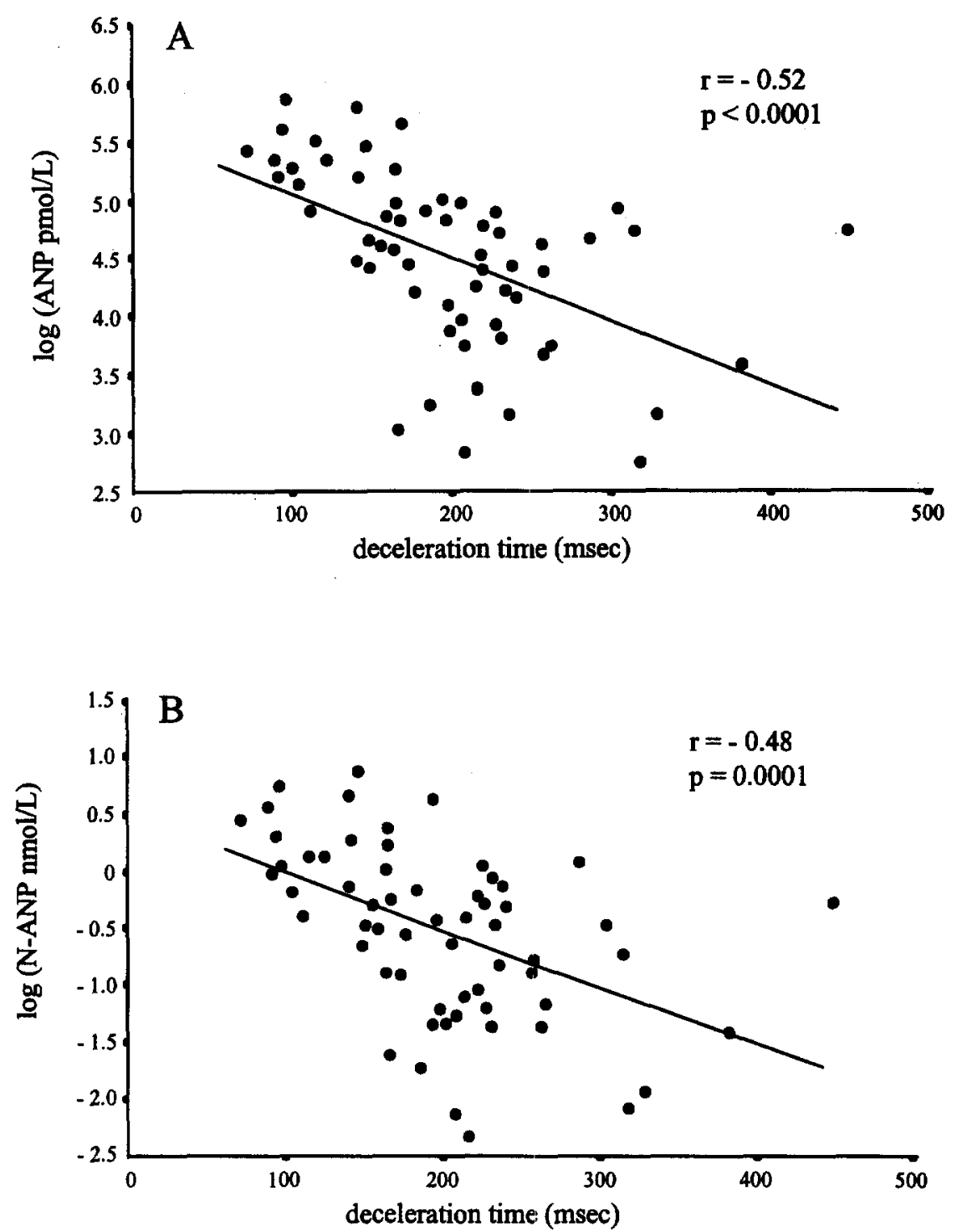

Fig. 2. Correlation between plasma concentrations of (A) atrial natriuretic peptide (ANP) and (B) N-terminal proANP and deceleration time.

ventricular filling [18], both age and an interaction term between age and left ventricular filling pattern (derived by multiplying age by filling pattern) were included in the analyses. The standardized regression coefficients $(\beta)$ and corresponding $P$ values are presented in Table 2. New York Heart Association functional class, use of diuretics and heart rate were included in the analyses, but appeared not to be related to ANP and N-terminal proANP concentrations. In addition to (restrictive) left ventricular filling pattern and left ventricular ejection fraction, age and the interaction term between age and filling pattern explained $57 \%\left(R^{2}=0.57\right)$ of the variation in ANP and $58 \%$ of the variation in N-terminal proANP. The presence of a restrictive left ventricular filling pattern by itself accounted for $39 \%$ of the variation in ANP and $36 \%$ of the variation in $\mathrm{N}$-terminal proANP. The linear regression models of the relation between left ventricular ejection fraction and plasma ANP and plasma $\mathrm{N}$-terminal proANP for patients with and without a restrictive left ventricular filling pattern graphically represent the contribution of the presence of a restrictive pattern to the plasma concentrations of atrial natriuretic peptides in patients with comparable left ventricular ejection fractions (Fig. 4).

\section{Discussion}

The present study shows that, in patients with chronic heart failure, elevated plasma concentrations of atrial natriuretic peptides are related to impaired left ventricular systolic function as well as abnormal left ventricular filling. Severity of systolic dysfunction and left ventricular filling abnormalities are important clinical and prognostic parameters in patients with heart failure due to coronary artery disease or dilated 

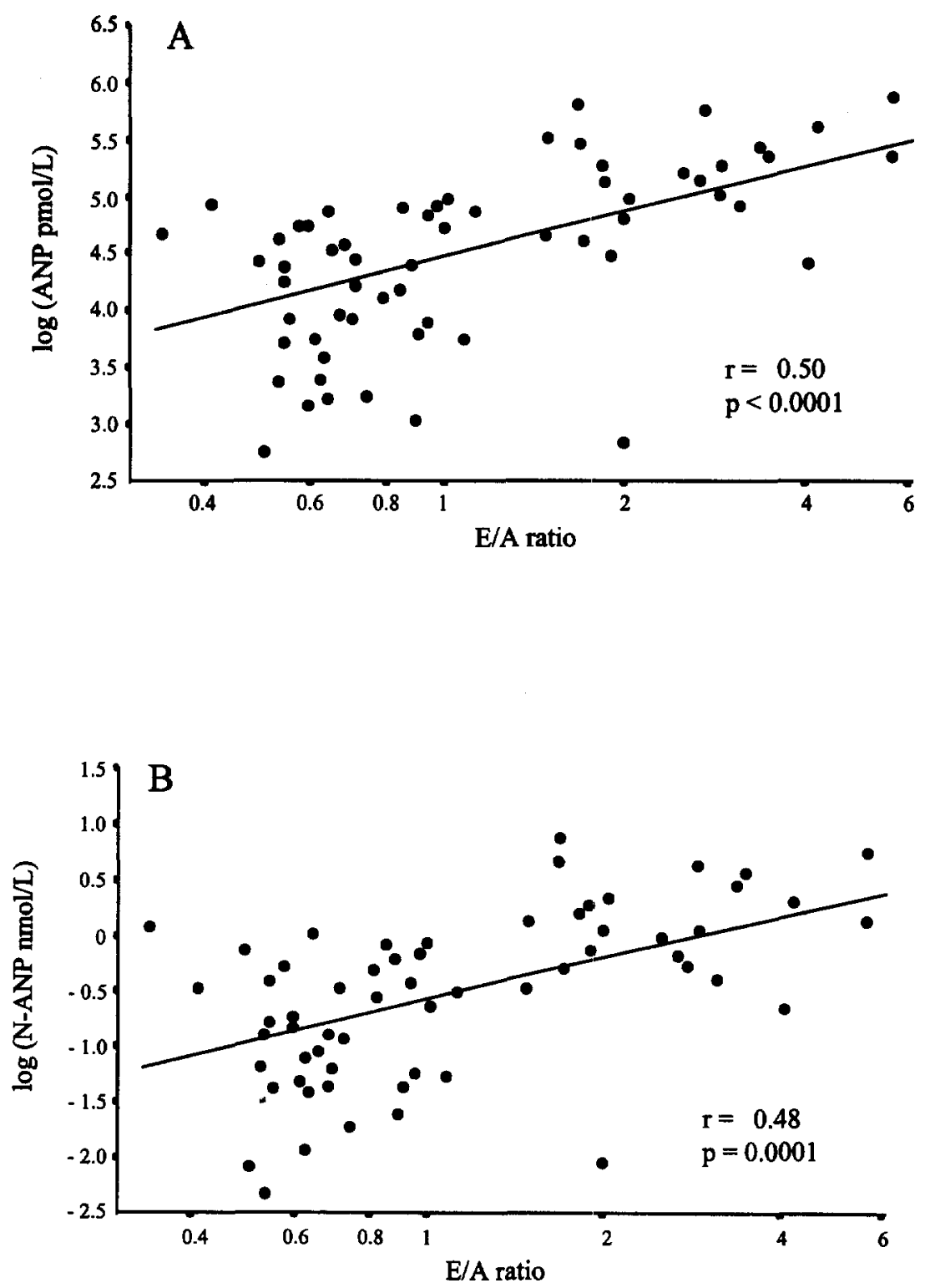

Fig. 3. Correlation between plasma concentrations of (A) atrial natriuretic peptide (ANP) and (B) N-terminal proANP and E/A ratio.

cardiomyopathy [7-9,19-21]. In both cardiac disorders, impaired left ventricular systolic function leads to progressive left ventricular dilatation and increased filling pressures. The accompanying reduction in left ventricular compliance, which results in a restrictive pattern of left ventricular filling, is associated with elevated filling pressures as well $[8,22]$. Thus, the present finding that both left ventricular systolic impairment and abnormal left ventricular filling are related to plasma atrial natriuretic peptide concentrations can be explained by the fact that systolic as well as diastolic dysfunction lead to increased filling pressures, and, as atrial natriuretic peptides are known to be released in response to atrial stretch or pressure $[1,2]$, to elevated plasma concentrations of atrial natriuretic peptides.

\subsection{Prior studies}

In contrast with the present results, plasma ANP was shown to be related to systolic but not to diastolic function in patients $24 \mathrm{~h}$ after myocardial infarction [23]. Furthermore, in patients with untreated essential hypertension a relation between a decreased $\mathrm{E} / \mathrm{A}$ ratio and elevated concentrations of ANP has been described [24], while in the present study higher ANP concentrations were found in patients with an increased $\mathrm{E} / \mathrm{A}$ ratio. As Doppler assessment of diastolic function is known to be dependent on systolic function [25], the results in hypertensives can not be compared with those in patients with heart failure due to left ventricular systolic dysfunction, nor can 
Table 2

Relation between atrial natriuretic peptide concentrations and left ventricular filling pattern, left ventricular ejection fraction and age - multivariate analysis

\begin{tabular}{|c|c|c|c|c|}
\hline \multirow[t]{2}{*}{ Variables } & \multicolumn{2}{|l|}{ ANP } & \multicolumn{2}{|c|}{$\mathrm{N}$-terminal proANF } \\
\hline & $\beta$ & $P$ values & $\beta$ & $P$ values \\
\hline $\begin{array}{l}\text { LV filling pattern } \\
\text { (restrictive) }\end{array}$ & 2.31 & $<0.0001$ & 2.00 & 0.0003 \\
\hline Age (years) & 0.51 & 0.0002 & 0.58 & $<0.0001$ \\
\hline $\begin{array}{l}\text { Age } \times \text { LV filling } \\
\text { pattern }\end{array}$ & -1.69 & 0.002 & -1.38 & 0.008 \\
\hline LVEF (\%) & -0.20 & 0.03 & -0.22 & 0.02 \\
\hline
\end{tabular}

Abbreviations: $\beta$, standardized regression coefficient; ANP, atrial natriuretic peptide; $\mathrm{N}$-terminal proANP, $\mathrm{N}$-terminal pro-atrial natriuretic peptide; $\mathrm{LV}$, left ventricular; Age $\times \mathrm{LV}$ filling pattern, interaction term between age and left ventricular filling pattern; LVEF, left ventricular ejection fraction. the results from our study be applied to patients with heart failure and normal systolic function.

\subsection{Study limitations}

Transmitral flow velocities are known to be affected by multiple factors, including age [18], heart rate [6] and mitral regurgitation [26]. Since both patient groups were comparable for age, heart rate and presence of more than mild mitral regurgitation, these variables are not considered to have influenced our results. In conformance with other reports $[7,8]$, patients with a restrictive filling pattern were more symptomatic and were using diuretics more frequently compared to patients with a non-restrictive pattern. However, these differences did not contribute to the outcome of
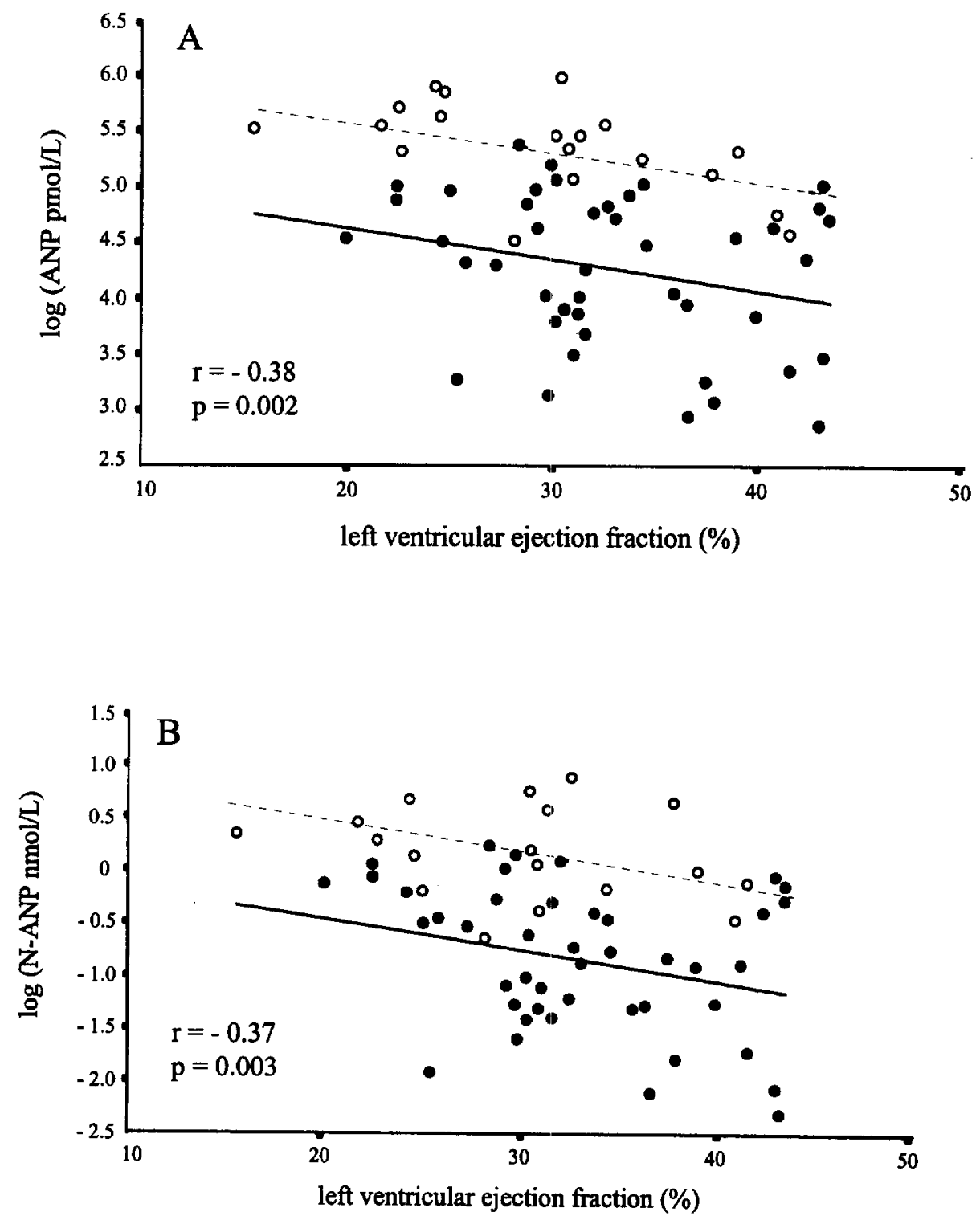

Fig. 4. Linear regression model of the relation between plasma concentrations of (A) atrial natriuretic peptide (ANP) and (B) N-terminal proANP and left ventricular ejection fraction for patients with restrictive $\left(\mathrm{O}_{-} .-\right)$and non-restrictive $(\bullet-)$ left ventricular filling patterns. 
multivariate analysis. The definitions for restrictive and non-restrictive filling patterns could be considered as arbitrary. Nevertheless, atrial natriuretic peptide concentrations did not only differ between patients with different filling patterns, but correlated with transmitral $\mathrm{E} / \mathrm{A}$ ratio and deceleration time as well. Finally, the time of the day that plasma samples were taken in relation to the time of drug administration might have been a source of variation in ANP and N-terminal proANP concentrations. Since all subjects were investigated in the late morning, $2-3 \mathrm{~h}$ after administration of heart failure medication, it was assumed that this contribution can be considered negligible.

\subsection{Conclusion}

In patients with chronic heart failure, elevated plasma concentrations of atrial natriuretic peptides are related to left ventricular systolic dysfunction as well as left ventricular filling abnormalities. This indicates that atrial natriuretic peptides can provide information on left ventricular systolic as well as diastolic function and points towards the potential value of determination of plasma atrial natriuretic peptides as a simple test for overall cardiac function in the assessment of patients with heart failure.

\section{References}

[1] Raine AE, Erne P, Burgisser $E$ et al. Atrial natriuretic peptide and atrial pressure in patients with congestive heart failure. N Engl J Med 1986;315:533-537.

[2] Richards AM, Cleland JG, Tonolo G et al. Plasma alpha natriuretic peptide in cardiac impairment. Br Med $\mathrm{J}$ (Clin Res Ed) 1986;293:409-412.

[3] Francis GS, Benedict C, Johnstone DE et al. Comparison of neuroendocrine activation in patients with left ventricular dysfunction with and without congestive heart failure. A substudy of the Studies of Left Ventricular Dysfunction (SOLVD). Circulation 1990;82:1724-1729.

[4] Lerman A, Gibbons RJ, Rodeheffer RJ et al. Circulating N-terminal atrial natriuretic peptide as a marker for symptomless left-ventricular dysfunction. Lancet 1993;341: $1105-1109$.

[5] Dickstein K, Larsen AI, Bonarjee V, Thoresen M, Aarsland $\mathrm{T}$, Hall C. Plasma proatrial natriuretic factor is predictive of clinical status in patients with congestive heart failure. Am J Cardiol 1995;76:679-683.

[6] Appleton CP, Hatle LK, Popp RL. Relation of transmitral flow velocity patterns to left ventricular diastolic function: new insights from a combined hemodynamic and Doppler echocardiographic study. J Am Coll Cardiol 1988;12:426-440.

[7] Vanoverschelde JL, Raphael DA, Robert AR, Cosyns JR. Left ventricular filling in dilated cardiomyopathy: relation to functional class and hemodynamics. J Am Coll Cardiol 1990);15:1288-1295.

[8] Pinamonti B, DiLenardi A, Sinagra G, Camerini F. Restrictive left ventricular filling pattern in dilated cardiomyopathy assessed by Doppler echocardiography: clinical, echocardiographic and hemodynamic correlations and prognostic implications. J Am Coll Cardiol 1993;22:808-815.

[9] Xie GY, Berk MR, Smith MD, Gurley JC, DeMaria AN. Prognostic value of Doppler transmitral flow patterns in patients with congestive heart failure. J Am Coll Cardiol 1994;24:132-139.

[10] Yu CM, Sanderson JE, Shum IOL et al. Diastolic dysfunction and natriuretic peptides in systolic heart failure. Eur Heart J 1996;17:1694-1702.

[11] Erbel R, Krebs W, Henn G et al. Comparison of single-plane and biplane volume determination by two-dimensional echocardiography. 1. Asymmetric model hearts. Eur Heart J 1982; 3:469-480.

[12] Helmcke F, Nanda NC, Hsiung MC et al. Color Doppler assessment of mitral regurgitation with orthogonal planes. Circulation 1987;75:175-183.

[13] Van der Borden SG, Roelandt J, Rijsterborgh. Computeraided analysis of Doppler echocardiograms. In: Roelandt $\mathbf{J}$, editor. Colour flow imaging and other advances in Doppler echocardiography. Dordrecht: Martinus Nijhoff Publishers, 1986:39-49.

[14] Appleton CP, Hatle LK, Popp RL. Demonstration of restrictive ventricular physiology by Doppler echocardiography. J Am Coll Cardiol 1988;11:757-768.

[15] Klein AL, Hatle LK, Taliercio CP et al. Prognostic significance of Doppler measures of diastolic function in cardiac amyloidosis. A Doppler echocardiography study. Circulation 1991;:83:808-816.

[16] Boomsma F, Bhaggoe UM, Man in 't Veld AJ, Schalekamp MA Comparison of N-terminal pro-atrial natriuretic peptide and atrial natriuretic peptide in human plasma as measured with commercially available radioimmunoassay kits. Clin Chim Acta 1996;252:41-49.

[17] Wallen T, Landahl S, Hedner T, Hedner J, Hall C. Atrial peptides, ANP(1-98) and ANP(99-126) in health and disease in an elderly population. Eur Heart J 1993;14:1508-1513.

[18] Pearson AC, Gudipati CV, Labovitz AJ. Effects of aging on left ventricular structure and function. Am Heart J 1991; 121:871-875.

[19] Rihal CS, Nishimura RA, Hatle LK, Bailey KR, Tajik AJ. Systolic and diastolic dysfunction in patients with clinical diagnosis of dilated cardiomyopathy. Relation to symptoms and prognosis. Circulation 1994;90:2772-2779.

[20] Giannuzzi P, Imparato A, Temporelli PL et al. Dopplerderived mitral deceleration time of early filling as a strong predictor of pulmonary capillary wedge pressure in postinfarction patients with left ventricular systolic dysfunction. J Am Coll Cardiol 1994;23:1630-1637.

[21] Xie GY, Berk MR, Smith MD, DeMaria AN. Relation of Doppler transmitral flow patterns to functional status in congestive heart failure. Am Heart J 1996;131:766-771.

[22] Nishimura RA, Appleton CP, Redfield MM, Ilstrup DM, Holmes DR, Tajik AJ. Noninvasive Doppler echocardiographic evaluation of left ventricular filling pressures in patients with cardiomyopathies: a simultaneous Doppler echocardiography and cardiac catheterization study. J Am Coll Cardiol 1996;28:1226-1233.

[23] Korup E, Toft E, Rasmussen K. Plasma atrial natriuretic peptide is related to systolic but not to diastolic myocardial function. Eur Heart J 1995;16:485-489. 
[24] Pontremoli R, Bezante GP, Robaudo $C$ et al. Cardiac diastolic abnormalities and atrial natriuretic factor in essential hypertension. Eur Heart J 1993;14:910-914.

[25] Himura $Y$, Kumada $T$, Kambayashi $M$ et al. Importance of left ventricular systolic function in the assessment of left ventricular diastolic function with Doppler transmitral flow velocity recording. J Am Coll Cardiol 1991;18:753-760.

[26] Takenaka K, Dabestani A, Gardin JM et al. Pulsed Doppler echocardiographic study of left ventricular filling in dilated cardiomyopathy. Am J Cardiol 1986;58:143-147. 